\title{
Editorial
}

\section{Enhancing Clinical Legal Education: Facing Challenges and Exploring}

\section{Possibilities}

Dr. Lyndsey Bengtsson

\section{Lyndsey2.bengtsson@northumbria.ac.uk}

In our spring edition, readers will benefit from an analysis of the variety of ways in which clinical legal education can be enhanced. Contributors consider how social justice teaching can be developed and the role clinics can play in supporting access to justice in the local community. We also delve into ways in which clinics can enhance reflection, legal analysis and our students' ability to both understand and implement approaches which might build trust with their clients.

Firstly, Jacqueline Weinberg's article explores the challenges of instilling in students the notion that social justice is important. One challenge is the expansion of clinical legal education and growth of externships where students are increasingly placed in law firms where their clients do not face barriers to access to justice. She explores how these challenges can be overcome to enhance students' awareness of the importance of social justice and ensure that it remains a value they retain as future practitioners. 
Another way in which social justice can be instilled in our students is through Exceptional Case Funding (ECF) clinics and this is the subject of Emma Marshall's article. She reflects on how setting up an ECF clinic offers students an opportunity to be involved with access to justice challenges in practice, whilst simultaneously improving access to legal aid by helping members of the public who need to access such funding. In her article she argues that ECF clinics serve an important function in supporting individuals to make applications, develop the students' legal skills and gain direct experience of access to justice issues.

Students also gain experience of access to justice issues from undertaking a clinical module which involves volunteer work at their local Citizens Advice. In an article from Lyndsey Bengtsson, Callum Thomson, and Bethany A'Court, the benefits and challenges of the module are explored through a semi structured interview with the academic responsible for the module's design and implementation. It is argued that the module not only develops students' professional skills, but also empowers students to better understand access to justice challenges and enables them to play a key part in supporting their local community.

Gemma Smyth, Dusty Johnstone, Jillian Rogin's article evaluates a trauma informed educational module for law students in clinical settings with clients who experience low income. Using open questions alongside a scenario, the authors analyse the effectiveness of the module and present their findings on how students interpret client behaviour before and after receiving trauma informed training. The results 
indicate that the students' ability to identify indicators of trauma in their clinical work increased, as did their ability to understand and implement approaches which might build trust with clients.

Also considering ways in which the students' clinical experience can be enhanced, Omar Madhloom explores how unregulated law clinics can engage with immigration clients. Although unregulated law clinics in England and Wales are prohibited from directly offering immigration advice, he argues that this should not be a barrier to teaching immigration law. In this article, he provides an insight into how using Kant's ethics as a focus can provide students with a framework for identifying their moral duties and serve as a useful analytical tool for enhancing student reflection and analysis of the law.

Finally, we have a 'From the Field' Report from Rachel Dunn, Siobhan McConnell and Lyndsey Bengtsson which provides information about the creation of a new Policy Clinic network and an upcoming free workshop hosted by CLEO. The workshop will take place on $13^{\text {th }}$ May 2021 via Zoom to share ideas for the network and future Policy Clinic/work ideas. The network aims to bring together academics who are, or want to, create impactful work through their teaching and engage with this kind education. All academics who are interested in this area, or who are involved in Policy Clinics/work and who wish to share best practice, are welcome to attend the workshop. 
In our winter Special Issue, we benefited from an initial analysis of the experience of law teachers living through the unprecedented challenge of the global pandemic and rapidly adjusting their practice to meet the needs of both their students and clients. Providing a flatform for us all to discuss the current challenges, and the extent to which they can be turned into opportunities, is this year's IJCLE conference. The conference is organised in partnership between the Global Alliance for Justice Education and Association for Canadian Clinical Legal Education and will take place on 16-18 June 2021.

The conference provides an opportunity to interact with fellow clinicians across the world in our new symposia. The conference also features the usual interactive workshops. For more information and instructions please see the attached link:

https://northumbria.ac.uk/about-us/news-events/turning-challenges-intoopportunities

The deadline for submission of your proposals and to take part in the conference is $7^{\text {th }}$ May 2021. Delegates are encouraged to submit their articles to the IJCLE for review following this conference. We hope to build upon the Special Issue with a future edition which focuses on clinics and their response to the Coronavirus pandemic. 